\title{
Systemic Therapy for Metastatic Non-Clear Cell Renal Carcinoma
}

\author{
Parham Khosravi-Shahi* \\ *Head of Medical Oncology Department, Hospital Universitario de Torrejón, Spain
}

Submission: March 29, 2016; Published: April 07, 2017

"Correspondence Address: Parham Khosravi-Shahi, Head of Medical Oncology Department, Hospital Universitario de Torrejón, Servicio de Oncología, Calle Mateo Inurria, s/n, Torrejón de Ardoz, Spain, Email: drkhosravi@hotmail.com

\begin{abstract}
Renal cell carcinoma (RCC) comprises $2-3 \%$ of all malignancies. Approximately $90 \%$ of renal tumors are RCCs, and $15 \%$ of these are non-clear cell tumors, which include papillary, chromophobe, Bellini duct (collecting duct) and sarcomatoid tumors. Antiangiogenic agents (sorafenib, sunitinib, pazopanib, temsirolimus, or bevacizumab), have not been specifically evaluated in phase III trials in patients with nonclear cell tumors. Therefore, their efficacy is unclear in the treatment of non-clear cell renal carcinomas. In a subset analysis of a randomized phase III trial, patients with non-clear cell and clear cell advanced RCCs, treated with temsirolimus, demonstrated comparable median overall and progression-free survival. In addition, temsirolimus resulted in a superior clinical benefit rate compared with interferon-alfa, regardless of tumor histology. Patients with metastatic papillary and chromophobe RCCs may have prolonged progression-free survival from sunitinib and sorafenib, although clinical responses remain overall low. Therefore, although there are some evidences supporting the use of these agents in patients with non-clear cell RCCs, additional prospective trials with these agents are needed to further clarify their use in these histologic subtypes. This review article focuses on all these options for non-clear cell advanced RCC.
\end{abstract}

\section{Introduction}

Renal cell carcinoma (RCC) accounts for $2-3 \%$ of all malignant diseases in adults. It is the seventh most common cancer in men and the ninth most common in women [1]. Incidence worldwide is about 209,000 new cases per year and 102,000 deaths per year. The incidence of all stages of this cancer has increased over several years, contributing to a steadily increasing mortality rate per unit population [2,3]. RCC is a male predominant

(2:1 ratio) disease with a typical presentation in the sixth and seventh decades of life (median age about 60 years). Patients with this cancer can present with local or systemic symptoms, although most presentations are incidental with the widespread use of abdominal imaging. Local signs and symptoms include haematuria, flank pain, or a palpable abdominal mass. Systemic symptoms can be due to metastases or paraneoplastic events [4].

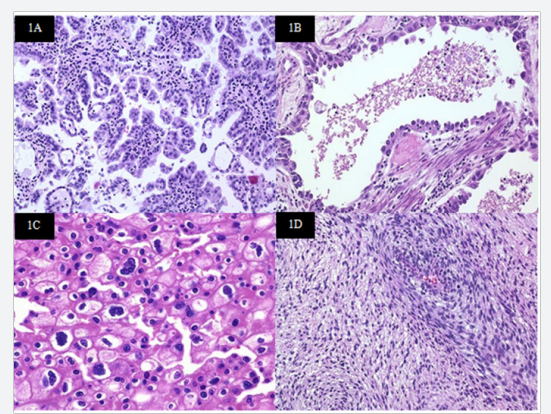

Figure 1: Non-clear cell renal cell carcinomas (RCC). 1A. Papillary RCC: the tumor cells lining papillary fronds have moderate amounts of eosinophilic cytoplasm and uniform round or oval nuclei with little atypical; 1B. Collecting Duct RCC: the tumor cells are arranged in duct-like structures, irregular nests or infiltrate singly. Hobnail appearance, seen clearly in this duct, is a helpful diagnostic feature; 1C. Chromophobe RCC: Microscopically, it is composed of variably-sized cells with abundant pale reticular or flocculent cytoplasm. The nuclei are moderately sized and hyper chromatic. Bi- and multinucleated cells are not uncommon. 1.D. Sarcomatoid RCC: Approximately $5 \%$ of RCC cases show sarcomatoid change. The sarcomatoid areas generally show features of fibrosarcoma, or undifferentiated spindle cell sarcoma. 
RCC, which accounts for $90 \%$ of renal tumors, is not a homogenous entity. A number of malignant histologic subtypes of RCC are recognized by the Heidelberg classification system [5], and clear cell carcinoma is the most common histologic subtype (85\%). Approximately $15 \%$ of the remaining RCCs are non-clear cell tumors, and include papillary, chromophobe, Bellini duct (collecting duct) and sarcomatoid tumors (Figure 1). Papillary and chromophobe RCCs represent the most common non-clear cell histologic subtypes with an incidence of $7 \%$ to $15 \%$ and $6 \%$ to $11 \%$, respectively [6]. Each RCC subtype is associated with unique genetic alterations, clinical characteristics, and sensitivity to treatment [7]

Recent advances in understanding the biology and genetics of RCC have led to major therapeutic implications. The role of the von Hippel-Lindau (VHL) gene in regulating proangiogenic factors has provided potential targets for novel agents. VHL gene inactivation, present in the majority of sporadic forms of RCC, leads to a defective VHL protein, followed by an active transcription of hypoxia-inducible genes, including vascular endothelial growth factor (VEGF), platelet-derived growth factor (PDGF), and others. Many of these gene products are involved in angiogenesis, tumor progression, and survival. However, the concept of VHL inactivation in RCC and the subsequent malignant phenotype is almost exclusively seen in patients with clear cell histology $[8,9]$.

Trials with small-molecule VEGF and PDGF receptor inhibitors, such as sunitinib, sorafenib and pazopanib have shown significant clinical activity in randomized trials in clear cell advanced RCC and have largely replaced cytokines as standard of care in this disease $[10,11]$. Earlier studies with cytokines agents showed minimal activity in patients with non-clear cell advanced RCC. These studies were mostly based on small series and case reports. Moreover, less than $10 \%$ of patients with non-clear cell histologist were included on clinical trials of new investigational agents, such as sunitinib, pazopanib and sorafenib. However, there are more data about the efficacy of temsirolimus in the treatment of non-clear cell advanced RCC [12]. On the other hand, some cytotoxic agents, such as gemcitabine and doxorubicin, have shown a moderate activity in sarcomatoid RCC.

\section{Non-Clear Cell Renal Cell Carcinomas}

Papillary RCC is the second most common histologic subtype of the kidney cancer, accounting for approximately $7 \%$ to $15 \%$ of cases, and nearly 29\% of all RCCs in African Americans. It can be further categorized histological into papillary types I and II [13]. Papillary type I RCC is associated with activating mutations of the methyl-nitro so-nitroguanidineinduced (MET) oncogene on the long arm of chromosome 7 [14]. These mutations result in ligand-independent activation of intracytoplasmic tyrosine kinase (TK) domains, which constitutively activate the hepatocytes growth factor/ MET pathway [15]. Papillary type II tumors occur both sporadically and in patients who have the familial syndrome of hereditary leiomyomatosis and renal cell carcinoma [16]. The genetic alteration associated with this syndrome has been localized to chromosome 1 and the gene identified as fumarate hydratase, which functions as a tumor suppressor, with both copies inactivated in tumors [17]. These tumors have characteristic large orangiophilic nuclei and a clear perinuclear halo, with a variety of architectural patterns such as papillary, tubulo-papillary, tubular, solid or mixed [18].

Chromophobe RCC accounts for approximately $6 \%$ to $11 \%$ of all RCCs, and is often detected while still confined to the kidney, as fewer than $5 \%$ of cases are metastatic at the time of diagnosis [19]. The mechanisms underlying the genesis of this subtype of RCC are not well understood. However, Birt-Hogg-Dubé (BHD) is an autosomal dominant hereditary cancer syndrome associated with bilateral, multifocal chromophobe RCC [20]. The BHD gene, FLCN, located on the short arm of chromosome 17, was identified by genetic linkage analysis, and is altered via insertion, deletion or nonsense mutations in the germline of the vast majority of affected individuals. The protein product of BHD, folliculin, functions as a tumor suppressor [21,22] .

Collecting duct RCC is extremely rare, accounting for less than $1 \%$ of all RCCs, and is associated with a grave prognosis, with approximately one-third of patients having metastases at the time of diagnosis. Sarcomatoid RCC is another rare histologic subtype of RCC, and is associated with poor prognosis. The median time to progression for advanced sarcomatoid renal tumors is approximately 2 months and median overall survival (OS) is 4 to 7 months [23].

\section{Efficacy of Multi-Kinase Inhibitors as First Line} Therapy: Sunitinib, Sorafenib and Pazopanib

Sunitinib is an orally administered inhibitor of multiple TKs, including VEGFR - $1,-2,-3)$, PDGFR (- $\alpha$ and- $\beta$ stem cell factor receptor (c-KIT), colony stimulating factor (CSF-1R) and neurotrophic factor receptor (RET) [24]. In a phase III trial, the efficacy of sunitinib in first line therapy was demonstrated in favorable-intermediate risk groups with predominantly clear cell advanced RCC. Sorafenib is another small molecule that inhibits multiple is forms of the intracellular serine/threonine kinase, RAF, and also other receptor TKs, including VEGFR-1, -2, -3 , PDGFR- $\beta$, FLT-3, c-KIT and RET $[25,26]$.

A randomized phase II trial investigated the efficacy and safety of sorafenib versus interferon-alpha-2a in previously untreated patients with predominantly clear cell advanced RCC [27]. In this study, sorafenib resulted in similar progression free survival (PFS) as interferon-alpha-2a in patients with untreated RCC (median PFS of 5.7 vs 5.6 months, respectively). However, sorafenib-treated patients experienced greater rates of tumor size reduction, better quality of life, and improved 


\section{Cancer Therapy \& Oncology International Journal}

tolerability. Pazopanib is also an oral angiogenesis inhibitor targeting VEGFR- $1,-2,-3$, PDGFR-, $\alpha-\beta$ and c-KIT. The efficacy and safety of pazopanib was evaluated in a phase III, openlabel, international, multicenter study. Four hundred thirtyfive patients with predominantly clear cell advanced RCC with no prior treatment or 1 prior cytokine-based treatment were randomized 2:1 to pazopanib or placebo. PFS was significantly prolonged with pazopanib compared with placebo in the overall study population (median PFS, 9.2 vs 4.2 months; hazard ratio [HR], 0.46; 95\% CI, 0.34 to $0.62 ; \mathrm{P}<0.0001$ ), the treatmentnaive subpopulation (median PFS, 11.1 vs 2.8 months; HR, 0.40; 95\% CI, 0.27 to $0.60 ; \mathrm{P}<0.0001$ ), and the cytokine-pretreated subpopulation (median PFS, 7.4 vs 4.2 months; HR, 0.54; $95 \%$ $\mathrm{CI}, 0.35$ to $0.84 ; \mathrm{P}<0.001$ ). The overall response rate (ORR) was $30 \%$ with pazopanib compared with $3 \%$ with placebo $(\mathrm{P}<$ 0.001 ) [28].

However, less than $10 \%$ of patients with non-clear cell histology's were included on clinical trials of new investigational agents, such as sunitinib, pazopanib and sorafenib. Therefore, their efficacy in non-clear cell RCCs is unclear. Recent data revealed that sunitinib and sorafenib is safe and may be efficacious in patients with non-clear cell tumors. In an expanded access trial, sunitinib was effective in the subgroup of patients with non-clear cell histology, as well as, patients with treated brain metastases and poor performance status (PS). In this study, 4,564 patients were enrolled in 52 countries, and 4,371 patients were included in the modified intention-to-treat population. This population included 588 patients (13\%) with non-clear cell RCCs. The ORR was $11 \%$ for non-clear cell RCCs. The median PFS was 10.9 months and median OS was 18.4 months. The most common grade 3-4 adverse events were fatigue (8\%) and thrombocytopenia (8\%), with incidences of grade 3-4 adverse events similar across subgroups [29].

In another study conducted by Choueiri et al. [30], the efficacy and safety of sunitinib and sorafenib was evaluated in patients with metastatic papillary and chromophobe RCCs. In this study, 53 patients were included, and the number of patients with papillary and chromophobe histologies was 41 (77\%) and $12(23 \%)$, respectively. The ORR, PFS, and OS for the entire cohort were $10 \%, 8.6$ months, and 19.6 months, respectively. Twenty-five percent of chromophobe RCCs achieved a response (two patients treated with sorafenib and one treated with sunitinib), and PFS was 10.6 months. Two (4.8\%) of 41 papillary RCC patients achieved a response (both patients were treated with sunitinib). Sunitinib-treated papillary RCC patients had a PFS of 11.9 months compared with 5.1 months for sorafenibtreated patients $(\mathrm{P}<.001)$. In conclusion, patients with papillary and chromophobe RCCs may have prolonged PFS from sunitinib and sorafenib, although clinical responses remain overall low in papillary RCC. On the other hand, the efficacy of pazopanib has not yet been studied in patients with non-clear cell RCCs. In summary, although there are some evidences supporting the use of these agents in patients with non-clear cell RCCs, additional prospective trials with these agents are needed to further clarify their use in these histologic subtypes.

\section{Temsirolimus as First Line Therapy}

Temsirolimus is an inhibitor of the mammalian Target of Rapamycin (mTOR) protein, which regulates micronutrients, cell growth, apoptosis and angiogenesis by its downstream effects on a variety of proteins. Efficacy and safety of temsirolimus was demonstrated in a multicenter, randomized, open-label phase III trial (Global Advanced Renal Cell Carcinoma [ARCC] trial) in previously untreated patients with advanced RCC who had at least 3 unfavorable prognostic factors [31]. In this trial, 626 patients were randomly assigned to receive $25 \mathrm{mg}$ of intravenous temsirolimus weekly, 3 million $U$ of interferon-alfa (with an increase to 18 million U) subcutaneously three times weekly, or combination therapy with $15 \mathrm{mg}$ of temsirolimus weekly plus 6 million $U$ of interferon-alfa three times weekly. As compared with interferon-alfa, patients who received temsirolimus alone had longer OS (HR, 0.73; $\mathrm{P}=0.008)$ and PFS $(\mathrm{P}<0.001)$ in the entire population. In the combination-therapy group OS did not differ significantly from that in the interferon group (HR, 0.96; $\mathrm{P}=0.70$ ). Median OS in the interferon group, the temsirolimus group, and the combination-therapy group were $7.3,10.9$, and 8.4 months, respectively.

Temsirolimus is the only agent that has shown activity in patients with non-clear cell RCCs in a subset analysis of ARCC trial [32]. Approximately $18 \%$ of patients had non-clear cell carcinoma, the majority of which were papillary. The baseline characteristics of patients with non-clear cell or clear cell histologies in the interferon and temsirolimus groups were generally balanced and similar to those of all patients in the study. Thirty-six (17\%) patients in the interferon group and 37 (18\%) patients in the temsirolimus groups had non-clear cell tumors. Patients with non-clear cell and clear cell advanced RCCs, treated with temsirolimus, had comparable median PFS (7.0 vs 5.5 months, respectively) and OS (11.6 vs 10.7 months, respectively). In contrast, patients with non-clear cell histology's treated with interferon demonstrated a shorter median OS than patients with tumors of clear cell histology (4.3 vs 8.2 months, respectively). As compared with interferon-alfa, patients with non-clear cell RCCs who received temsirolimus had longer PFS (median 1.8 vs 7.0 months; HR, 0.38, 95\% confidence interval [CI]: 0.23-0.62) and OS (median 4.3 vs 11.6 months; HR, 0.49, 95\% CI: 0.29-0.85); (Table 1). In addition, temsirolimus resulted in a superior clinical benefit rate compared with interferonalfa, regardless of tumor histology. Therefore, temsirolimus is a category 1 recommendation for first-line treatment in patients with non-clear cell advanced RCCs with poor prognosis features. 


\section{Cancer Therapy \& Oncology International Journal}

Table 1: Overall and progression-free survival in patients with advanced renal cell carcinoma treated with interferon-alfa and temsirolimus in ARCC trial.

\begin{tabular}{|c|c|c|c|c|c|c|}
\hline \multirow{2}{*}{$\begin{array}{l}\text { Primary } \\
\text { cell type }\end{array}$} & \multicolumn{2}{|c|}{$\begin{array}{c}\text { Median PFS } \\
\text { (months) }\end{array}$} & \multirow{2}{*}{$\begin{array}{c}\text { Hazard } \\
\text { Ratio } \\
(95 \% \mathrm{CI})\end{array}$} & \multicolumn{2}{|c|}{$\begin{array}{c}\text { Median OS } \\
\text { (months) }\end{array}$} & \multirow{2}{*}{$\begin{array}{c}\text { Hazard } \\
\text { Ratio } \\
(95 \% \mathrm{CI})\end{array}$} \\
\hline & IFN & Tem & & IF & Tem & \\
\hline $\begin{array}{c}\text { Non } \\
\text { clear cell }\end{array}$ & 1.8 & 7.0 & $\begin{array}{c}0.38 \\
(0.23-0.62)\end{array}$ & 4.3 & 11.6 & $\begin{array}{c}0.49 \\
(0.29-0.85)\end{array}$ \\
\hline Clear cell & 3.7 & 5.5 & $\begin{array}{c}0.76 \\
(0.60-0.97)\end{array}$ & 8.2 & 10.7 & $\begin{array}{c}0.82 \\
(0.64-1.06)\end{array}$ \\
\hline
\end{tabular}

PFS: Progression-Free Survival; OS: Overall Survival; IFN: Interferon; Tem: Temsirolimus; CI: Confidence Interval.

\section{Chemotherapy and Erlotinib}

Chemotherapy is another therapeutic option for patients with non-clear cell advanced RCCs, especially for sarcomatoid and collecting duct histologies. Sarcomatoid RCCs are rare and aggressive tumors associated with poor outcome, and there is no a standard therapy for them. Immunotherapy and antiangiogenic therapies are generally ineffective in sarcomatoid RCCs. However, different cytotoxic agents, such as gemcitabine and doxorubicin, have a modest antitumor activity in these tumors. In a study conducted by Nanus, et al. [33], gemcitabine in combination with doxorubicin was evaluated in patients with sarcomatoid RCCs. In this study, 18 patients with advanced RCC (56\% with sarcomatoid tumors and $44 \%$ with other histologies) were treated with a regimen consisting of doxorubicin $50 \mathrm{mg} / \mathrm{m} 2$ and gemcitabine 1,500-2,000 mg/m2, administered every two weeks with growth factor support. Two patients had a complete response (CR), five had a partial response (PR), and two patients had stable disease of more than 6 months of duration, and the median duration of response was 5 months (range, 2-21 months). This therapy was generally well tolerated with no grade 4 toxicities. Among the 18 patients, four were long-term survivors [34].

Collecting duct RCCs account for less than 1\% of all RCCs, and is associated with a grave prognosis. Due to the rarity of this disease, there is scant evidence to guide treatment recommendations, and no randomized clinical trials have been completed. In a phase II trial, 23 patients with collecting duct advanced RCCs were treated with gemcitabine plus cisplatin or carboplatin, depending on renal function. This regimen was selected based on the histologic similarities between collecting duct RCC and transitional cell carcinoma of the urinary bladder. The ORR was $26 \%$ (5 PR and $1 \mathrm{CR}$ ) as measured by an independent radiologic review. The median PFS of the study was 7.1 months, and the median OS was 10.5 months [35]. Based on this study, gemcitabine plus cisplatin is the most recommended treatment for collecting duct advanced RCCs.

Another TK inhibitor, erlotinib, has also been evaluated in the treatment of non-clear cell advanced RCCs. Erlotinib is an oral epidermal growth factor receptor TK inhibitor. In a multicenter phase II trial, 52 patients with locally advanced and metastatic papillary RCCs were treated with this agent. The ORR of this study was $11 \%$, and the disease control rate was $64 \%$. The 6-month PFS was only 29\%; however, the median OS was 27 months. There was one grade 5 adverse event (AE) of pneumonitis, one grade 4 thromboses, and nine other grades 3 AEs [36]. Despite of these interesting results, there is no enough evidence to recommend the use of erlotinib in the treatment of non-clear cell RCCs.

\section{Conclusion}

Non-clear cell RCCs account for 15\% of all RCCs, and each histologic subtype is associated with unique genetic alterations, clinical characteristics, and sensitivity to treatment. Antiangiogenic agents (sorafenib, sunitinib, pazopanib, everolimus or bevacizumab), have not been tested in phase III trials in patients with non-clear cell tumors. Therefore, their efficacy is unclear in the treatment of non-clear cell RCCs. In a subset analysis of a phase III trial (ARCC trial), patients with non-clear cell and clear cell advanced RCCs with poor prognosis, treated with temsirolimus, demonstrated comparable median PFS and OS.

In addition, temsirolimus resulted in a superior clinical benefit rate compared with interferon-alfa, regardless of tumor histology. Hence, temsirolimus is a category 1 recommendation for first-line treatment in patients with non-clear cell advanced RCCs with poor prognosis features. Patients with metastatic papillary and chromophobe RCCs may have prolonged PFS from sunitinib and sorafenib, although clinical responses remain overall low. Therefore, although there are some evidences supporting the use of these agents in patients with non-clear cell RCCs, additional prospective trials with these agents are needed to further clarify their use in these histologic subtypes. On the other hand, some cytotoxic agents combinations, such as gemcitabine plus doxorubicin or gemcitabine plus cisplatin, have shown a moderate activity in sarcomatoid and collecting duct advanced RCCs, respectively.

\section{Reference}

1. Gupta K, Miller JD, Li JZ, Russell MW, Charbonneau C (2008) Epidemiologic and socioeconomic burden of metastatic renal cell carcinoma (mRCC): a literature review. Cancer Treat Rev 34(3): 193205.

2. Hollingsworth JM, Miller DC, Daignault S, Hollenbeck BK (2006) Rising incidence of small renal masses: a need to reassess treatment effect. J Natl Cancer Inst 98(18): 1331-1334.

3. Hollingsworth JM, Miller DC, Daignault S, Hollenbeck BK (2007) Fiveyear survival after surgical treatment for kidney cancer: a populationbased competing risk analysis. Cancer 109(9): 1763-1768.

4. Rini BI (2009) Metastatic Renal Cell Carcinoma: Many Treatment Options, One Patient. J Clin Oncol 27(19): 3225-3234.

5. Pfaffenroth EC, Linehan WM (2008) Genetic basis for kidney cancer: opportunity for disease-specific approaches to therapy. Expert Opin Biol Ther 8(6): 779-790. 


\section{Cancer Therapy \& Oncology International Journal}

6. Reuter VE (2006) The pathology of renal epithelial neoplasms. Semin Oncol 33(5): 534-543.

7. Linehan WM, Srinivasan R, Schmidt LS (2010) The genetic basis of kidney cancer: a metabolic disease. Nat Rev Urol 7(5): 277-285.

8. Choueiri TK, Bukowski RM, Rini BI (2006) The current role of angiogenesis inhibitors in the treatment of renal cell carcinoma. Semin Oncol 33(5): 596-606.

9. Motzer RJ, Bander NH, Nanus DM (1996) Renal-cell carcinoma. N Engl J Med 335(12): 865-875.

10. Motzer RJ, Hutson TE, Tomczak P, Bycott PW, Baum CM, et al. (2007) Sunitinib versus interferon alfa in metastatic renal cell carcinoma. N Engl J Med 356(2): 115-124.

11. Escudier B, Eisen T, Stadler WM, Hutson TE, Gore M, et al. (2007) Sorafenib in advanced clear-cell renal-cell carcinoma. N Engl J Med 356(2): 125-134.

12. Hudes G, Carducci M, Tomczak P, Moore L, Motzer RJ, et al. (2007) Temsirolimus, interferon alfa, or both for advanced renal-cell carcinoma. N Engl J Med 356(22): 2271-2281.

13. Cohen HT, McGovern FJ (2005) Renal-cell carcinoma. N Engl J Med 353 2477-2490.

14. Dharmawardana PG, Giubellino A, Bottaro DP (2004) Hereditary papillary renal carcinoma type I. Curr Mol Med 4(8): 855-868.

15. Sudarshan S, Linehan WM (2006) Genetic basis of cancer of the kidney. Semin Oncol 33(5): 544-551.

16. Launonen V, Vierimaa O, Kiuru M, Herva R, Aaltonen LA, et al. (2001) Inherited susceptibility to uterine leiomyomas and renal cell cancer Proc Natl Acad Sci U S A 98(6): 3387-3392.

17. Tomlinson IP, Alam NA, Rowan AJ, Paetau A, Salovaara R, et al. (2002) Germline mutations in FH predispose to dominantly inherited uterine fibroids, skin leiomyomata and papillary renal cell cancer. Nat Genet 30(4): 406-410.

18. Merino MJ, Torres-Cabala C, Pinto P, Linehan WM (2007) The morphologic spectrum of kidney tumors in hereditary leiomyomatosis and renal cell carcinoma (HLRCC) syndrome. Am J Surg Pathol 31(10):1578-1585.

19. Cheville JC, Lohse CM, Zincke H, Weaver AL, Blute ML (2003) Comparisons of outcome and prognostic features among histologic subtypes of renal cell carcinoma. Am J Surg Pathol 27(5): 612-624.

20. Pavlovich CP, Walther MM, Eyler RA, et al. (2002) Renal tumors in the Birt-Hogg-Dubé syndrome. Am J Surg Pathol 26(12): 1542-1552.

21. Schmidt LS, Warren MB, Nickerson ML, Vera Matrosova, ${ }^{2}$ Jorge R Toro, et al. (2001) Birt-Hogg-Dubé syndrome, a genodermatosis associated with spontaneous pneumothorax and kidney neoplasia, maps to chromosome 17p11.2. Am J Hum Genet 69(4): 876-882.

22. Vocke CD, Yang Y, Pavlovich CP, Zbar B, Linehan WM, et al. (2005) High frequency of somatic frameshift bhd gene mutations in Birt-HoggDubé-associated renal tumors. J Natl Cancer Inst 97(12): 931-935.

23. Motzer RJ, Bacik J, Mariani T, Russo P, Mazumdar M, Reuter V (2002)
Treatment outcome and survival associated with metastatic renal cell carcinoma of non-clear-cell histology. J Clin Oncol 20(9): 2376-2381.

24. Motzer RJ, Michaelson MD, Redman BG, Bello CL, Theuer CP, et al (2006) Activity of SU11248, a multitargeted inhibitor of vascular endothelial growth factor receptor and platelet-derived growth factor receptor, in patients with metastatic renal cell carcinoma. J Clin Oncol 24(1): 16-24

25. Awada A, Hendlisz A, Gil T, Schwartz B, Piccart M, et al. (2005) Phase I safety and pharmacokinetics of BAY 43-9006 administered for 21 days on/7 days off in patients with advanced, refractory solid tumours. Br J Cancer 92(10): 1855-1861.

26. Clark JW, Eder JP, Ryan D, Lathia C, Lenz HJ (2005) Safety and pharmacokinetics of the dual action Raf kinase and vascular endothelial growth factor receptor inhibitor, BAY 43-9006, in patients with advanced, refractory solid tumors. Clin Cancer Res 11(15): 5472 5480 .

27. Escudier B, Szczylik C, Hutson TE, Shah S, Bukowski RM, et al. (2009) Randomized phase II trial of first-line treatment with sorafenib versus interferon Alfa-2a in patients with metastatic renal cell carcinoma. J Clin Oncol 27(8): 1280-1289.

28. Sternberg CN, Davis ID, Mardiak J, McCann L, Pandite L, et al. (2010) Pazopanib in locally advanced or metastatic renal cell carcinoma: results of a randomized phase III trial. J Clin Oncol 28(6): 1061-1068.

29. Gore ME, Szczylik C, Porta C, Schöffski P, Mainwaring P, et al. (2009) Safety and efficacy of sunitinib for metastatic renal-cell carcinoma: an expanded-access trial. Lancet Oncol 10: 757-763.

30. Choueiri TK, Plantade A, Elson P, Bukowski RM, Escudier B, et al. (2008) Efficacy of sunitinib and sorafenib in metastatic papillary and chromophobe renal cell carcinoma. J Clin Oncol 26: 127-131.

31. Hudes G, Carducci M, Tomczak P, Robert Figlin, Anil Kapoor, et al (2007) Temsirolimus, interferon alfa, or both for advanced renal-cell carcinoma. N Engl J Med 356: 2271-2281.

32. Dutcher JP, de Souza P, McDermott D, Feingold J, Hudes G, et al. (2009) Effect of temsirolimus versus interferon-alpha on outcome of patients with advanced renal cell carcinoma of different tumor histologies. Med Oncol 26(2): 202-209.

33. Nanus DM, Garino A, Milowsky MI, Larkin M, Dutcher JP (2004) Active chemotherapy for sarcomatoid and rapidly progressing renal cell carcinoma. Cancer 101:1545-1251.

34. Dutcher JP, Nanus D (2010) Long-term survival of patients with sarcomatoid renal cell cancer treated with chemotherapy. Med Oncol 28(4): 1530-1533.

35. Oudard S, Banu E, Vieillefond A, Medioni J, Banu A, et al. (2007) Prospective multicenter phase II study of gemcitabine plus platinum salt for metastatic collecting duct carcinoma: results of a GETUG (Groupe d'etudes des tumeurs uro-genitales) study. J Urol 177:16981702 .

36. Gordon MS, Hussey M, Nagle RB, Pan CX, Crawford D, et al. (2009) Phase II study of erlotinib in patients with locally advanced or metastatic papillary histology renal cell cancer SWOG S0317. J Clin Oncol 27(34): 5788-5793. 


\section{Your next submission with Juniper Publishers} will reach you the below assets

- Quality Editorial service

- Swift Peer Review

- Reprints availability

- E-prints Service

- Manuscript Podcast for convenient understanding

- Global attainment for your research

- Manuscript accessibility in different formats ( Pdf, E-pub, Full Text, Audio)

- Unceasing customer service

Track the below URL for one-step submission https://juniperpublishers.com/online-submission.php 